\title{
Faktor yang Mempengaruhi Skor APGAR Menit Pertama pada Seksio Sesarea dengan Anestesi Spinal
}

\author{
Ide Pustaka Setiawan ${ }^{1}$, Diah Rumekti Hadiati ${ }^{2}$ Ahsanudin Attamimi ${ }^{3}$ \\ 1,2,3 Departemen Obstetri dan Ginekologi FK-KMK UGM \\ Korespondensi: idepustaka@gmail.com
}

Submisi: 5 September 2019; Revisi: 11 Oktober 2019; Penerimaan: 22 November 2019

\begin{abstract}
Background: Cesarean section lead to morbidity and mortality consequencies of mother and newborn. The morbidity of mother in cesarean section should not be followed by morbidity of newborn especially the low of APGAR score which lead to asphyxia. Risk factors affecting the low of the first minute APGAR score during cesarean section with spinal anesthesia needed to be well understood to mimimize newborn asphyxia.

Objective: The aim of this study was to understand factors affecting the the low of first minute APGAR score in cesarean section with spinal anesthesia. Method: This was crssectional study. The study was conducted by direct observation of elective cesarean section with spinal anesthesia. The first minute APGAR score of newborn was assessed. Chi Square test, Fisher Exact test and Mann-Whitney test were used to do bivariate analysis. Logistic regression used for multivariate analysis. All statistical analysis were done by SPSS 21.

Results and Discussion: There were 93 subjects fulfilled inclusion and exclusion criteria. The decrease of systolic blood pressure (RR 1.05; Cl 0.40-2.75; $p=1.00$ ), the decrease of diastolic blood pressure ( $R R 0.93 ; \mathrm{Cl} \mathrm{0.33-2.59;} p=0.56)$, the decrease of Mean Arterial Pressure ( $R R$ 0.72; $C l 0.28-1.86$; $\mathrm{p}=0.35$ ) after anesthesia induction, the lengthening of skin incision to delivery interval $\geq 5.5$ minutes ( $R R 1.63 ; \mathrm{Cl} 0.65-4.12 ; p=0.44)$ and the low of $\mathrm{Hb}$ value before surgery (RR 1.22; $\mathrm{Cl} 0.44-3.37 ; \mathrm{p}=0.47$ ) were not correlate significantly with the first minute APGAR score $<7$ of the newborn delivered by cesarean section with spinal anesthesia. Whereas anesthesia induction to delivery interval $\geq 12.5$ minutes $(\mathrm{RR} 2.91 ; \mathrm{Cl} 1.10-7.72 ; \mathrm{p}=0.04)$ and uterine incision to delivery interval $\geq 3$ minutes ( $R R 3.48 ; \mathrm{Cl} 1.51-8.02 ; \mathrm{p}=0,01$ ) were strongly correlated and significant both statistically as well as clinically to cause the first minute APGAR score $<7$ of the newborn delivered by cesarean section with spinal anesthesia.

Conclusion: Factors affecting the low of first minute APGAR score in cesarean section with spinal anesthesia were anesthesia induction to delivery interval $\geq 12.5$ minutes and uterine incision to delivery interval $\geq 3$ minutes.
\end{abstract}

Keywords: cesarean section; asphyxia; spinal anesthesia; APGAR score.

\begin{abstract}
ABSTRAK
Latar Belakang: Seksio sesarea membawa konsekuensi morbiditas dan mortalitas pada ibu dan bayi. Morbiditas ibu pada seksio sesarea seyogyanya tidak diikuti dengan kejadian morbiditas pada bayi khususnya rendahnya nilai skor APGAR sehingga berpotensi menjadi asfiksia pada bayi baru lahir. Faktor risiko terjadinya asfiksia yang dinilai dari rendahnya skor APGAR pada bayi baru lahir saat dilakukan secara seksio sesarea dengan anestesi spinal perlu diketahui agar ada usaha untuk meminimalisasi kejadian asfiksia tersebut.

Tujuan: Tujuan penelitian ini adalah untuk mengetahui faktor-faktor yang mempengaruhi rendahnya skor APGAR menit pertama pada seksio sesarea dengan anestesi spinal.

Metode: Penelitian ini adalah studi observasional dengan rancangan penelitian crossectional study dengan cara observasi langsung proses seksio sesarea elektif yang menggunakan anestesi spinal dan dilihat luaran skor APGAR bayi baru lahir pada menit pertama. Uji statistik yang digunakan untuk analisis bivariat adalah uji Chi Square, Fisher Exact serta Mann-Whitney. Sedangkan analisis multivariat dilakukan dengan uji regresi logistik. Pengolahan data untuk pengujian statistik menggunakan SPSS 21.

Hasil dan Pembahasan: Terdapat 93 subjek memenuhi kriteria inklusi dan eksklusi dalam penelitian ini. Terjadinya penurunan tekanan darah sistolik ( $R R$ 1,05; $\mathrm{Cl} 0,40-2,75 ; p=1,00$ ), terjadinya penurunan tekanan darah diastolik ( $R R 0,93 ; \mathrm{Cl} 0,33-2,59 ; p=0,56$ ), terjadinya penurunan $\mathrm{MAP}$ (RR 0,$72 ; \mathrm{Cl}$ $0,28-1,86 ; p=0,35)$ pasca induksi anestesi, pemanjangan waktu insisi kulit hingga bayi lahir $\geq 5,5$ menit $(\mathrm{RR} 1,63 ; \mathrm{Cl} 0,65-4,12 ; \mathrm{p}=0,44)$ dan rendahnya kadar $\mathrm{Hb}$ sebelum operasi (RR 1,22; $\mathrm{Cl} 0,44-3,37 ; \mathrm{p}=0,47$ ) berhubungan tidak signifikan dengan rendahnya skor APGAR menit pertama pada seksio sesarea dengan anestesi spinal. Sedangkan interval waktu induksi anestesi hingga bayi lahir $\geq 12,5$ menit $(\mathrm{RR} 2,91 ; \mathrm{Cl} 1,10-7,72 ; \mathrm{p}=0,04)$ dan interval waktu insisi uterus hingga bayi lahir $\geq 3$ menit ( $R R 3,48 ; \mathrm{Cl} 1,51-8,02 ; p=0,01)$ berhubungan kuat serta bermakna secara signifikan baik secara statistik maupun klinis menyebabkan skor APGAR menit pertama $<7$ pada bayi baru lahir secara seksio sesarea dengan anestesi spinal.

Kesimpulan: Faktor-faktor yang mempengaruhi rendahnya skor APGAR menit pertama pada seksio sesarea dengan anestesi spinal adalah interval waktu induksi anestesi hingga bayi lahir $\geq 12,5$ menit dan interval waktu insisi uterus hingga bayi lahir $\geq 3$ menit.
\end{abstract}

Kata kunci: seksio sesarea; asfiksia; anestesi spinal; skor APGAR 


\section{PENDAHULUAN}

Angka persalinan seksio sesarea di dunia terus meningkat. ${ }^{1}$ Pada tahun 1970-an terdapat 5-7\% angka persalinan seksio sesarea dari seluruh persalinan, hingga tahun 1987 angka tersebut terus meningkat dengan tajam menjadi $24,4 \%$. Di Indonesia sendiri angka seksio sesarea meningkat tajam terutama di kota-kota besar. Berdasarkan data Riskesdas 2010 menunjukkan angka seksio sesarea sebesar 15,3\%, terendah di Sulawesi Tenggara 5,5\% dan tertinggi di DKI Jakarta 27,2\%. ${ }^{1}$

Berbagai upaya diusahakan agar persalinan seksio sesarea dapat diturunkan dan terus ditekan hingga stabil di kisaran 5-15\%. ${ }^{1}$ Dengan meningkatnya seksio sesarea maka probabilitas terjadinya morbiditas pada ibu maupun pada bayi yang dilahirkan juga mengalami peningkatan.

Asfiksia adalah salah satu morbiditas seksio sesarea yang menjadi masalah serius pada neonatus di seluruh dunia. Menurut WHO sebanyak 4 juta kematian per tahun yang terjadi pada bayi disebabkan oleh asfiksia bayi baru lahir dan hal ini merupakan $38 \%$ penyumbang kematian anak di bawah 5 tahun. ${ }^{2}$ Insidensi asfiksia bayi baru lahir adalah 1-6 per 1000 kelahiran bayi aterm. ${ }^{3}$ Kejadian asfiksia sebisa mungkin dicegah agar luaran bayi lebih baik dan mencegah gejala sisa yang menetap di kemudian hari. Nilai APGAR diharapkan dapat memberikan prediksi status neurologik dan survival pada bayi. ${ }^{4}$

Banyak faktor yang menyebabkan bayi baru lahir menjadi asfiksia, di antaranya adalah faktor maternal, faktor fetal dan jenis persalinan. ${ }^{4}$ Bayi asfiksia dapat dilahirkan pada jenis persalinan vaginal spontan, vakum ekstraksi, maupun seksio sesarea baik emergensi maupun terencana. ${ }^{4,5}$ Seksio sesarea yang membawa konsekuensi morbiditas dan mortalitas pada ibu, akan lebih baik jika tidak diikuti dengan morbiditas pada bayi khususnya asfiksia atau rendahnya nilai skor APGAR. Untuk itu diperlukan suatu kajian untuk mengetahui faktor risiko yang mempengaruhi rendahnya skor APGAR pada bayi saat dilakukan secara seksio sesarea sehingga diharapkan ada upaya untuk meminimalisasi kejadian asfiksia tersebut.

Tujuan penelitian ini adalah untuk mengetahui apakah penurunan tekanan darah, interval waktu induksi anestesi hingga bayi lahir, interval waktu insisi kulit hingga bayi lahir, interval waktu insisi uterus hingga bayi lahir dan kadar $\mathrm{Hb}$ sebelum operasi mempengaruhi rendahnya skor APGAR menit pertama pada seksio sesarea dengan anestesi spinal?

\section{METODE}

Penelitian ini adalah penelitian observasional dengan rancangan crossectional dengan cara observasi langsung proses seksio sesarea elektif yang menggunakan anestesi spinal di RSUP dr. Sardjito, RSUD Sleman, RSUD Wates dan RSUD Bantul kemudian dilihat luaran skor APGAR bayi baru lahir pada menit pertama. Kurun waktu pengambilan data adalah pada bulan September 2017. Proses pengambilan data dihentikan setelah jumlah sampel minimal terpenuhi.

Populasi dan subjek pada penelian ini adalah ibu hamil yang menjalani seksio sesarea yang memenuhi kriteria iklusi dan eksklusi. Subjek penelitian dijelaskan jalannya penelitian dan diminta persetujuannya dengan menandatangi lembar keikutsertaan dalam penelitian sebelum operasi dalam keadaan tenang tanpa pengaruh dari pihak manapun dan dalam kondisi belum masuk dalam persalinan.

Kriteria inklusi adalah semua seksio sesarea elektif baik yang seksio sesarea pertama kali maupun seksio sesarea ulangan dengan menggunakan anestesi spinal sesuai dengan prosedur anestesi spinal yang diseragamkan, pada kehamilan aterm dengan janin dalam kondisi sehat. Sedangkan kriteria eksklusi adalah ibu dengan penyakit penyerta PEB, DM, Ketuban Pecah Dini, perdarahan antepartum banyak, usia kehamilan preterm, usia kehamilan lewat waktu, IUGR, kelainan kongenital dan fetal distress atau fetal compromised.

Analisis data yang digunakan adalah uji analisis univariat, bivariat serta multivariat. Uji statistik yang digunakan untuk analisis bivariat adalah uji Chi Square dan uji Fisher. ${ }^{6}$ Uji statistik yang digunakan untuk analisis multivariat adalah uji regresi logistik. Pengolahan data untuk pengujian statistik menggunakan SPSS 21. 


\section{HASIL DAN PEMBAHASAN}

\section{Analisis univariat}

Pada bulan September 2017 terdapat total 233 operasi bedah sesar dari keempat rumah sakit, yang terdiri dari RSUP Sardjito 42 operasi, RSUD Sleman
78 operasi, RSUD Bantul 33 operasi dan RSUD Wates 80 operasi. Dari total operasi bedah sesar tersebut, yang memenuhi kriteria inklusi dan eksklusi adalah sejumlah 93 subjek. Karakteristik data dan subjek penelitian ditampilkan pada tabel 1.

Tabel 1. Karakteristik data penelitian

\begin{tabular}{llrr}
\hline \multicolumn{1}{c}{ Karakteristik } & & N & Persentase \\
\hline Nama Rumah Sakit & RSUP Sardjito & 3 & $3,2 \%$ \\
& RSUD Sleman & 19 & $20,4 \%$ \\
& RSUD Bantul & 31 & $33,3 \%$ \\
& RSUD Wates & 40 & $43 \%$ \\
Penurunan sistolik & Ya & 63 & $67,7 \%$ \\
& Tidak & 30 & $32,3 \%$ \\
Penurunan diastolik & Ya & 71 & $76,3 \%$ \\
& Tidak & 22 & $23,7 \%$ \\
Penurunan MAP & Ya & 70 & $75,3 \%$ \\
& Tidak & 23 & $24,7 \%$ \\
Interval waktu induksi anestesi & $\geq 20$ menit & 9 & $9,7 \%$ \\
hingga bayi lahir & $<20$ menit & 84 & $90,3 \%$ \\
Interval waktu insisi kulit hingga & $\geq 10$ menit & 11 & $11,8 \%$ \\
bayi lahir & $<10$ menit & 82 & $88,2 \%$ \\
Interval waktu insisi uterus & $\geq 3$ menit & 17 & $18,3 \%$ \\
hingga bayi lahir & $<3$ menit & 76 & $81,7 \%$ \\
Hb pre operasi (g/dL) & Hb <11 g/dl & 20 & $21,5 \%$ \\
Skor APGAR menit pertama & Hb $\geq 11$ g/dl & 73 & $78,5 \%$ \\
& $<7$ & 77 & $82,8 \%$ \\
\hline
\end{tabular}

\section{Analisis bivariat}

Hubungan variabel bebas dengan variabel tergantung diuji statistik dengan uji Chi Square dan Fisher's Exact test tergantung dari penerimaan $\mathrm{X}^{2}$ (tabel 2).

Hubungan variabel luar dengan variabel tergantung dapat dilihat pada tabel 3. Terdapat 3 variabel yang bisa dilakukan penyesuaian nilai potong agar didapatkan nilai potong yang optimal. Ketiga variabel tersebut adalah interval waktu induksi anestesi hingga bayi lahir, interval waktu insisi kulit hingga bayi lahir dan interval waktu insisi uterus hingga bayi lahir. Untuk itu dilakukan analisis ROC dengan melihat Area Under the Curve (AUC), serta grafik perpotongan sensitifitas dan spesifisitas. 
Tabel 2. Hubungan Penurunan tekanan darah dengan skor APGAR menit pertama

\begin{tabular}{|c|c|c|c|c|c|c|c|}
\hline \multirow{2}{*}{ Variabel } & \multicolumn{4}{|c|}{ Skor APGAR menit pertama } & \multirow{2}{*}{ p } & \multirow{2}{*}{$\mathbf{R R}$} & \multirow{2}{*}{ Cl 95\% } \\
\hline & $<7$ & $\%$ & $\geq 7$ & $\%$ & & & \\
\hline \multicolumn{8}{|c|}{ Penurunan sistolik } \\
\hline $\mathrm{Ya}$ & 11 & 17,5 & 52 & 82,5 & $1,00^{\mathrm{a}}$ & 1,05 & $0,40-2,75$ \\
\hline Tidak & 5 & 16,7 & 25 & 83,3 & & & \\
\hline \multicolumn{8}{|c|}{ Penuruan diastolik } \\
\hline Ya & 12 & 16,9 & 59 & 83,1 & $0,56^{b}$ & 0,93 & $0,33-2,59$ \\
\hline Tidak & 4 & 18,2 & 18 & 81,8 & & & \\
\hline \multicolumn{8}{|l|}{ Penurunan MAP } \\
\hline Ya & 11 & 15,7 & 59 & 84,3 & $0,35^{b}$ & 0,72 & $0,28-1,86$ \\
\hline Tidak & 5 & 21,7 & 18 & 78,3 & & & \\
\hline
\end{tabular}

${ }^{a}$ Chi-square, ${ }^{b}$ Fisher Exact

Tabel 3. Hubungan antara variabel luar dengan skor APGAR menit pertama

\begin{tabular}{|c|c|c|c|c|c|c|c|}
\hline \multirow{2}{*}{ Variabel } & \multicolumn{4}{|c|}{ Skor APGAR menit pertama } & \multirow{2}{*}{$\mathbf{p}$} & \multirow{2}{*}{$\mathbf{R R}$} & \multirow{2}{*}{$\mathrm{Cl} 95 \%$} \\
\hline & $<7$ & $\%$ & $\geq 7$ & $\%$ & & & \\
\hline \multicolumn{8}{|c|}{ Interval waktu induksi anestesi hingga bayi lahir } \\
\hline$\geq 20$ menit & 4 & 44,4 & 5 & 55,6 & $0,04^{\mathrm{a}}$ & 3,11 & $1,27-7,64$ \\
\hline$<20$ menit & 12 & 14,3 & 72 & 85,7 & & & \\
\hline \multicolumn{8}{|c|}{ Interval waktu insisi kulit hingga bayi lahir } \\
\hline$\geq 10$ menit & 3 & 27,3 & 8 & 72,7 & $0,29^{a}$ & 1,72 & $0,58-5,10$ \\
\hline$<10$ menit & 13 & 15,9 & 69 & 84,1 & & & \\
\hline \multicolumn{8}{|c|}{ Interval waktu insisi uterus hingga bayi lahir } \\
\hline$\geq 3$ menit & 7 & 41,2 & 10 & 58,8 & $0,01^{\mathrm{a}}$ & 3,48 & $1,51-8,02$ \\
\hline$<3$ menit & 9 & 11,8 & 67 & 88,2 & & & \\
\hline \multicolumn{8}{|l|}{ Kadar Hb maternal pre op } \\
\hline$<11 \mathrm{~g} / \mathrm{dL}$ & 4 & 20 & 16 & 80 & $0,47^{\mathrm{a}}$ & 1,22 & $0,44-3,37$ \\
\hline$\geq 11 \mathrm{~g} / \mathrm{dL}$ & 12 & 16,4 & 61 & 83,6 & & & \\
\hline
\end{tabular}

${ }^{\text {a}}$ Fisher Exact

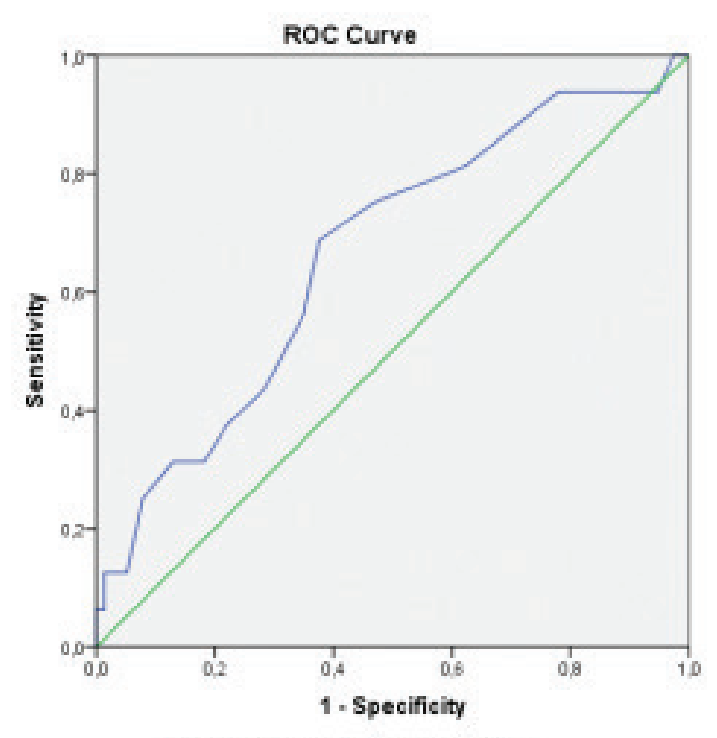

Diagonal sagments are produced by ties.

Gambar 1. Kurva ROC interval waktu induksi anestesi hingga bayi lahir
Tabel 4. Area Under the Curve interval waktu induksi anestesi hingga bayi lahir

\begin{tabular}{cccc}
\hline Area & Std. Error & $\begin{array}{c}\text { Asymptotic } \\
\text { Sig. }\end{array}$ & $\begin{array}{c}\text { Asymptotic } \\
\text { Cl 95\% }\end{array}$ \\
\hline 0,66 & 0,08 & 0,04 & $0,52-0,81$ \\
\hline
\end{tabular}

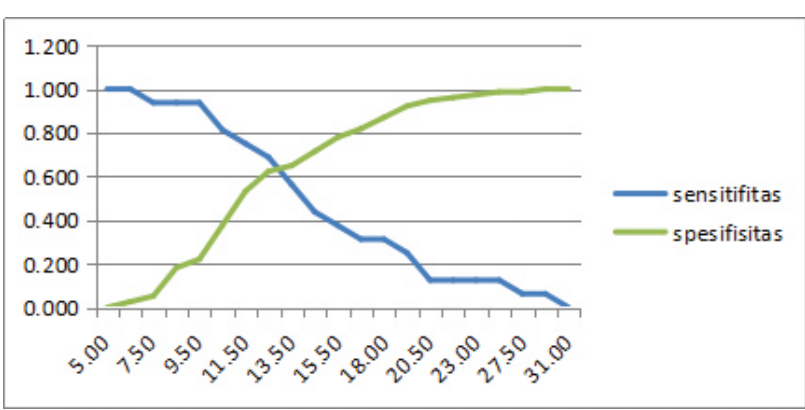

Gambar 2. Grafik sensitifitas spesifisitas: interval waktu induksi anestesi hingga bayi lahir 
Tabel 5. Hubungan interval waktu induksi anestesi hingga bayi lahir $\geq 12,5$ menit dengan skor APGAR menit pertama

\begin{tabular}{|c|c|c|c|c|c|c|c|}
\hline \multirow{2}{*}{ Variabel } & \multicolumn{4}{|c|}{ Skor APGAR menit pertama } & \multirow{2}{*}{$\mathbf{p}$} & \multirow{2}{*}{$\mathbf{R R}$} & \multirow{2}{*}{$\mathrm{Cl} 95 \%$} \\
\hline & $<7$ & $\%$ & $\geq 7$ & $\%$ & & & \\
\hline$\geq 12,5$ menit & 11 & 27,5 & 29 & 72,5 & $0,04^{a}$ & 2,91 & $1,10-7,72$ \\
\hline$<12,5$ menit & 5 & 9,4 & 48 & 90,6 & & & \\
\hline
\end{tabular}

${ }^{a}$ Chi-square

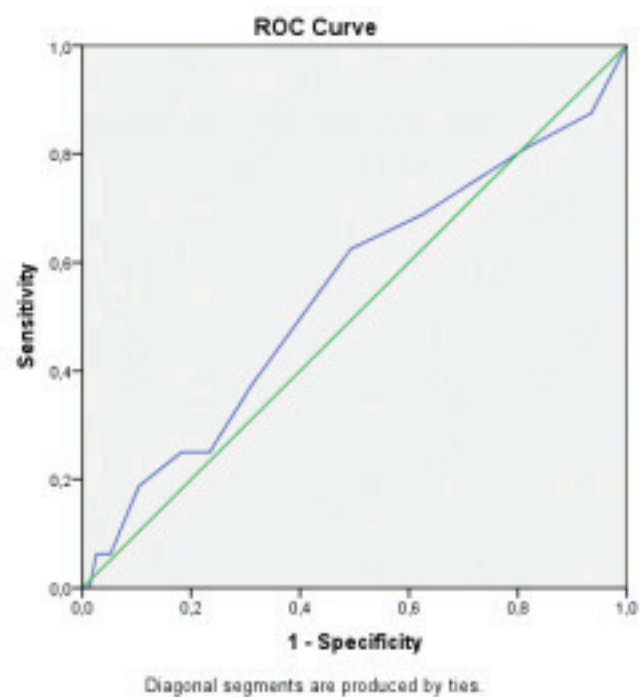

Gambar 3. Kurva ROC interval waktu insisi kulit hingga bayi lahir
Tabel 6. Area Under the Curve interval waktu insisi kulit hingga bayi lahir

\begin{tabular}{cccc}
\hline Area & Std. Error & $\begin{array}{c}\text { Asymptotic } \\
\text { Sig. }\end{array}$ & $\begin{array}{c}\text { Asymptotic } \\
\text { Cl 95\% }\end{array}$ \\
\hline 0,55 & 0,08 & 0,58 & $0,38-0,71$ \\
\hline
\end{tabular}

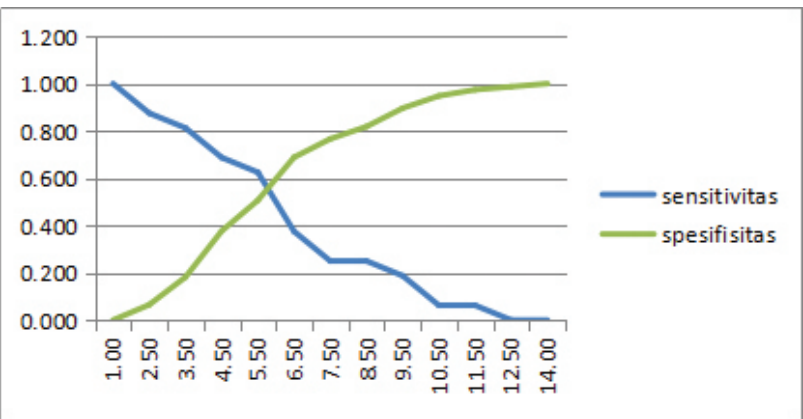

Gambar 4. Grafik sensitifitas spesifisitas: interval waktu insisi kulit hingga bayi lahir

Tabel 7. Hubungan interval waktu insisi kulit hingga bayi lahir $\geq 5,5$ menit dengan skor APGAR menit pertama

\begin{tabular}{|c|c|c|c|c|c|c|c|}
\hline \multirow{2}{*}{ Variabel } & \multicolumn{4}{|c|}{ Skor APGAR menit pertama } & \multirow{2}{*}{ p } & \multirow{2}{*}{ RR } & \multirow{2}{*}{ CI 95\% } \\
\hline & $<7$ & $\%$ & $\geq 7$ & $\%$ & & & \\
\hline$\geq 5,5$ menit & 10 & 21,3 & 37 & 78,7 & $0,44^{\mathrm{a}}$ & 1,63 & $0,65-4,12$ \\
\hline$<5,5$ menit & 6 & 13 & 40 & 87 & & & \\
\hline
\end{tabular}

${ }^{\mathrm{a} C h i}$-square

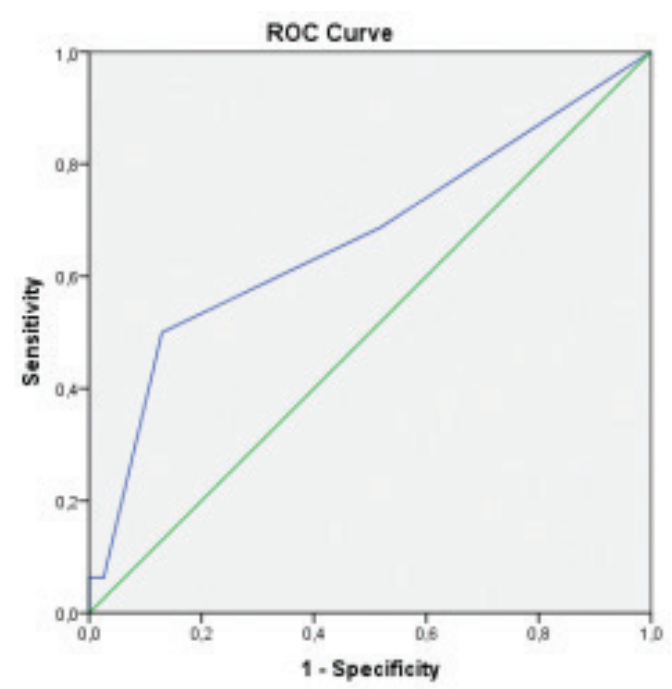

Diagonal sagments are produced by ties.

Gambar 5. Kurva ROC interval waktu insisi uterus hingga bayi lahir
Tabel 8. Area Under the Curve interval waktu insisi uterus hingga bayi lahir

\begin{tabular}{cccc}
\hline Area & Std. Error & $\begin{array}{c}\text { Asymptotic } \\
\text { Sig. }\end{array}$ & $\begin{array}{c}\text { Asymptotic } \\
\text { Cl 95\% }\end{array}$ \\
\hline 0,67 & 0,08 & 0,04 & $0,50-0,83$ \\
\hline
\end{tabular}

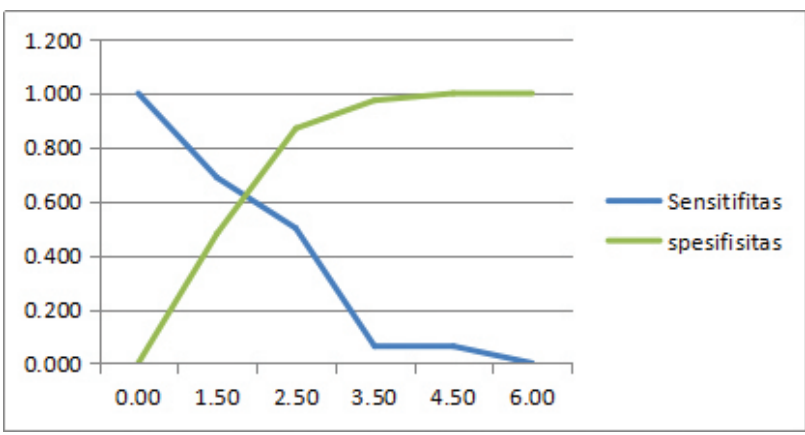

Gambar 6. Grafik sensitifitas spesifisitas: interval waktu insisi uterus hingga bayi lahir 
Tabel 9. Hubungan interval waktu insisi uterus hingga bayi lahir $\geq 1,5$ menit dengan skor APGAR menit pertama

\begin{tabular}{|c|c|c|c|c|c|c|c|}
\hline \multirow{2}{*}{ Variabel } & \multicolumn{4}{|c|}{ Skor APGAR menit pertama } & \multirow{2}{*}{$\mathbf{p}$} & \multirow{2}{*}{$\mathbf{R R}$} & \multirow{2}{*}{$\mathrm{Cl} 95 \%$} \\
\hline & $<7$ & $\%$ & $\geq 7$ & $\%$ & & & \\
\hline$\geq 1,5$ menit & 11 & 21,6 & 40 & 78,4 & $0,219^{a}$ & 1,81 & $0,68-4,80$ \\
\hline$<1,5$ menit & 5 & 11,9 & 37 & 88,1 & & & \\
\hline
\end{tabular}

${ }^{a}$ Chi-square

Tabel 10. Analisis multivariat pengaruh antar variabel terhadap skor APGAR menit pertama

\begin{tabular}{lccc}
\hline \multicolumn{1}{c}{ Variabel } & RR & Cl 95\% & p \\
\hline $\begin{array}{l}\text { Interval waktu induksi anestesi hingga bayi lahir } \\
\quad \geq 12,5 \text { menit }\end{array}$ & 2,94 & $0,89-9,73$ & 0,08 \\
$\quad<12,5$ menit & & & \\
Interval waktu insisi uterus hingga bayi lahir & & & 0,02 \\
$\quad \geq 3$ menit & 4,23 & $1,24-14,46$ & \\
$\quad<3$ menit & & & \\
\hline
\end{tabular}

Gambar 1 dan tabel 4 menjelaskan kurva ROC interval waktu induksi anestesi hingga bayi lahir dengan AUC sebesar 66\%. Area ini berbeda bermakna dengan nilai AUC 50\% ( $p<0,05 \mathrm{Cl} 0,52-$ 0,81 ). Gambar 2 menjelaskan nilai potong interval waktu induksi anestesi hingga bayi lahir mempunyai sensitivitas dan spesifisitas paling optimal pada nilai potong 12,5 menit. Dari tabel 5 dapat diketahui bahwa interval waktu induksi anestesi hingga bayi lahir $\geq 12,5$ menit berhubungan bermakna secara statistik ( $p<0,04 \mathrm{Cl} 1,10-7,72$ ) serta mempunyai probabilitas sebesar 2,91 kali menyebabkan skor APGAR menit pertama $<7$.

Gambar 3 dan tabel 6 menjelaskan kurva ROC interval waktu insisi kulit hingga bayi lahir dengan AUC sebesar $55 \%$. Area ini tidak berbeda bermakna dengan nilai AUC 50\% ( $p>0,05)$. Gambar 4 menjelaskan nilai potong interval waktu insisi kulit hingga bayi lahir yang mempunyai sensitivitas dan spesifisitas paling optimal yaitu pada nilai potong 5,5 menit. Dari tabel 7 dapat diketahui bahwa interval waktu insisi kulit hingga bayi lahir $\geq 5,5$ menit berhubungan tidak bermakna secara statistik ( $p>0,44 \mathrm{Cl} 0,65-4,12$ ) serta mempunyai probabilitas sebesar 1,63 kali menyebabkan skor APGAR menit pertama $<7$.

Gambar 5 dan tabel 8 menjelaskan kurva ROC interval waktu insisi uterus hingga bayi lahir dengan AUC sebesar $67 \%$. Area ini berbeda bermakna dengan nilai AUC 50\% ( $p<0,04 \mathrm{Cl} 0,50-0,83)$. Gambar 6 menjelaskan nilai potong interval waktu insisi uterus hingga bayi lahir yang mempunyai sensitivitas serta spesifisitas paling optimal yaitu pada nilai potong 1,5 menit. Dari tabel 9 dapat diketahui bahwa interval waktu insisi uterus hingga bayi lahir $\geq 1,5$ menit tidak berhubungan bermakna secara statistik $(p>0,05 \mathrm{Cl}$ $0,68-4,80)$ serta mempunyai probabilitas sebesar 1,81 kali menyebabkan skor APGAR menit pertama $<7$. Karena hasil analisis bivariat pada nilai potong 1,5 menit tidak signifikan, maka variabel insisi uterus hingga bayi lahir tetap menggunakan nilai potong 3 menit yang mempunyai nilai spesifisitas tertinggi serta signifikan secara statistik.

\section{Analisis Multivariat}

Variabel yang memenuhi syarat dilakukan analisis multivariat adalah variabel dengan nilai $p<0,25$ yaitu: interval waktu induksi anestesi hingga bayi lahir $\geq 12,5$ menit dan interval waktu insisi uterus hingga bayi lahir $\geq 3$ menit.

Hasil analisis multivariat (tabel 10) diperoleh bahwa interval waktu induksi anestesi hingga bayi lahir $\geq 12,5$ menittidak berpengaruh bermakna secara statistik $(p>0,05)$ namun secara klinis mempunyai probabilitas sebesar 2,94 kali menyebabkan skor APGAR menit pertama $<7$. Sedangkan interval waktu insisi uterus hingga bayi lahir $\geq 3$ menit berpengaruh bermakna secara $(p<0,05)$ dengan probabilitas sebesar 4,23 kali menyebabkan skor APGAR menit pertama $<7$. 
Penurunan tekanan darah merupakan satu komplikasi yang sering terjadi pada anestesi spinal. Dari tabel 1 dapat dilihat bahwa mayoritas subjek mengalami penurunan tekanan darah sistolik, diastolik dan MAP. Pada penelitian ini tidak dihitung besar dan lama penurunan tekanan darah yang terjadi pada pasien. Hal ini mungkin menyebabkan penurunan tekanan darah pada penelitian ini tidak berhubungan bermakna dengan rendahnya skor APGAR menit pertama.

Pemanjangan interval waktu induksi anestesi hingga bayi lahir dalam kondisi anestesi spinal, berhubungan dengan penurunan skor APGAR. ${ }^{7}$ Pada penelitian ini terdapat hubungan interval waktu induksi anestesi hingga bayi lahir dengan rendahnya skor APGAR menit pertama (tabel 3). Pada nilai potong 20 menit hubungan ini bermakna secara statistik, begitu juga pada nilai potong 12,5 menit (tabel 3, tabel 5). Nilai potong 12,5 menit adalah nilai potong paling optimal yang mempengaruhi secara signifikan skor APGAR menit pertama < 7 (gambar 2). Meskipun nilai potong antara penelitian ini dengan penelitian lain berbeda namun terdapat kesamaan bahwa semakin panjangnya interval waktu induksi anestesi hingga bayi lahir mempengaruhi rendahnya nilai skor APGAR. Hal ini terjadi karena terdapat penurunan aliran darah uteroplacenta oleh karena blokade saraf simpatis saat anestesi spinal. Semakin panjang interval waktu induksi anestesi hingga bayi lahir maka semakin panjang juga penurunan aliran darah uteroplasenta. Hal inilah yang menyebabkan penurunan luaran bayi baru lahir. ${ }^{7}$

Interval waktu insisi kulit hingga bayi lahir berhubungan tidak bermakna dengan skor APGAR menit pertama (tabel 3). Pada gambar 4 dapat dilihat bahwa waktu insisi kulit hingga bayi lahir $\geq 5,5$ menit mempunyai nilai sensitifitas dan spesifisitas yang paling optimal. Namun dari tabel 7 dapat diketahui bahwa terdapat hubungan yang tidak signifikan antara interval waktu insisi kulit hingga bayi lahir dengan skor APGAR menit pertama. Sumber lain menyarankan waktu insisi kulit hingga bayi lahir lebih dari 8 menit berhubungan dengan hipoksia pada fetus dan asidosis tanpa melihat jenis anestesi. $^{9}$

Tabel 3 menunjukkan bahwa terdapat hubungan bermakna secara statistik antara interval waktu insisi uterus hingga bayi lahir dengan skor APGAR menit pertama pada nilai potong 3 menit. Nilai potong paling optimal yang mempengaruhi skor APGAR menit pertama $<7$ adalah 1,5 menit (gambar 6 ), namun secara statistik nilai potong $\geq 1,5$ menit tidak berhubungan secara signifikan dengan skor APGAR menit pertama $<7$ dengan nilai $p>0,05$ (tabel 9). Untuk itu nilai potong variabel insisi uterus hingga bayi lahir yang digunakan adalah 3 menit karena mempunyai nilai spesifisitas tertinggi serta berhubungan statistik secara signifikan dengan skor APGAR menit pertama $<7 \quad(p=0,01 ; R R 3,48)$. Nilai potong tersebut sama dengan penelitian yang lain. Interval waktu insisi uterus hingga bayi lahir lebih dari 3 menit berhubungan dengan hipoksia pada fetus dan asidosis tanpa melihat jenis anestesi. ${ }^{9}$ Peningkatan waktu insisi uterus hingga bayi lahir berhubungan dengan peningkatan kadar norepinefrin arteri umbilical, menurunkan $\mathrm{pH}$ arteri umbilical dan menurunkan skor APGAR menit pertama. ${ }^{10}$ Terpecahnya selaput ketuban oleh operator saat bedah sesar mungkin mempunyai andil dalam penurunan skor APGAR jika terjadi pemanjangan waktu insisi uterus hingga bayi lahir, namun hal ini belum belum banyak diketahui.

Kadar $\mathrm{Hb}$ maternal pre operasi pada nilai potong $11 \mathrm{~g} / \mathrm{dL}$ berhubungan dengan rendahnya skor APGAR menit pertama namun tidak bermakna secara statistik $(p>0,05)$ (tabel 3$)$. Penelitian lain menyebutkan bahwa konsentrasi $\mathrm{Hb}$ yang abnormal meningkatkan risiko berat badan lahir rendah dan rendahnya skor APGAR, sehingga perawatan secara intensive perlu diperhatikan khususnya pada ibu dengan anemia. ${ }^{11}$

\section{KESIMPULAN DAN SARAN}

Kesimpulan yang dapat diambil dari dari penelitian ini adalah:

1. Pemanjangan interval waktu induksi anestesi hingga bayi lahir $\geq 12,5$ menit dan pemanjangan interval waktu insisi uterus hingga bayi lahir $\geq 3$ menit, berhubungan secara signifikan dengan rendahnya skor APGAR menit pertama pada seksio sesarea dengan anestesi spinal.

2. Terjadinya penurunan tekanan darah pasca induksi anestesi spinal, Pemanjangan interval 
waktu insisi kulit hingga bayi lahir, Rendahnya kadar $\mathrm{Hb}$ sebelum operasi, berhubungan lemah dan tidak bermakna dengan rendahnya skor APGAR menit pertama pada seksio sesarea dengan anestesi spinal.

\section{DAFTAR PUSTAKA}

1. Andayasari, L., Muljati, S., Sihombing, M., Arlinda, D., Opitasari, C., Moksa, D.F., Widianto. 2015. Proporsi Seksio Sesarea dan Faktor yang Berhubungan dengan Seksio Sesarea di Jakarta. Buletin Penelitian Kesehatan, 43(2), pp.105-116.

2. Aslam, H.M., Saleem, S., Afzal, R., Iqbal, U., Saleem, S.M., Waqas, M., Shaikh, A., Shahid, N. 2014. Risk Factors of Birth Asphyxia. Italian Journal Pediatrics, pp.1-9.

3. Antonucci, R., Porcella, A. \& Pilloni, M.D., 2014. Perinatal Asphyxia in the Term Newborn. Journal of Pediatric and Neonatal Individualized Medicine, 3(2), pp.1-14.

4. Utomo, M.T., 2011. Risk Factors for Birth Asphyxia. Folia Medica Indonesiana, 47(4), pp.211-214.

5. Benzounia, S., Boubkraoui, M.E., Mreabet, M., Chahid, N., Kharbach, A., El-Hassani, A., Barkat, A. 2016. Fetal Outcome in Emergency Versus Elective Cesarean Sections at Souissi Maternity Hospital, Rabat, Morocco. Pan African Medical Journal, 23(197), pp. 1-9.
6. Dahlan S. Statistik Untuk Kedokteran dan Kesehatan. 6th ed. Jakarta: Epidemioligi Indonesia; 2016.

7. Palan, A. \& Agrawal, N.K., 2016. Effect of Induction Delivery Time on Apgar Score in Lower Segment Cesarean Section Under Spinal Anesthesia., 9(1), pp.20-23.

8. Chooi, C., Cox, J.J., Lumb, R.S., Middlelton, P., Chemali, M., Emmet, R.S., Simmons, S.W., Cyna, A.M. 2017. Techniques for preventing hypotension during spinal anaesthesia for caesarean section (review). Cochrane Database of Systematic Reviews, (8). Available at: http://doi.wiley.com/ 10.1002/ 14651858.CD002251

9. Morgan, G.J. \& Mikhail, M., 2013. Clinical Anaesthesiology 5th ed., Stamford: Appleton \& Lange.

10. Orbach - Zinger, S. \& Ginosar, Y., 2013. Effects on the fetus of General Versus Regional Anesthesia. Anesthesia and the fetus. Chicester.

11. Alizadeh, L., Raoofi, A., Salehi, L., Ramzi, M. 2014. Impact of Maternal Hemoglobin Concentration on Fetal Outcomes in Adolescent Pregnant Women. Iranian Red Crescent Medical Journal, 16(8), pp.1-5. 